OPEN ACCESS

Edited by:

Guoyang Fu,

Monash University, Australia

Reviewed by:

Laurent Olivier Louis,

New England Research, United States

Shida Xu,

Northeastern University, China

*Correspondence:

Yuan Zhao

zhaoyuan92@csu.edu.cn

Lianjun Chen

creejxk@163.com

Specialty section: This article was submitted to Interdisciplinary Physics,

a section of the journal

Frontiers in Physics

Received: 07 August 2020 Accepted: 30 November 2020

Published: 15 January 2021

Citation:

Zhou Z, Zhou J, Zhao Y, Chen L and Li C (2021) Microscopic Failure Mechanism Analysis of Rock Under Dynamic Brazilian Test Based on Acoustic Emission and Moment Tensor Simulation.

Front. Phys. 8:592483.

doi: $10.3389 /$ fphy.2020.592483

\section{Microscopic Failure Mechanism Analysis of Rock Under Dynamic Brazilian Test Based on Acoustic Emission and Moment Tensor Simulation}

\author{
Zilong Zhou ${ }^{1}$, Jing Zhou ${ }^{1}$, Yuan Zhao ${ }^{1 *}$, Lianjun Chen ${ }^{2 *}$ and Chongjin $\mathrm{Li}^{1}$ \\ ${ }^{1}$ School of Resources and Safety Engineering, Central South University, Changsha, China, ${ }^{2}$ Key Laboratory of Mining Disaster \\ Prevention and Control, Qingdao, China
}

The dynamic tensile failure of rock is a main failure mode in deep underground engineering projects. The microscopic failure mechanism analysis of this failure mode plays a key role in dynamic disaster warning. Moment tensor inversion is a very well-known method used to analyze failure mechanisms. However, an acoustic emission (AE) event cannot be accurately distinguished in rock dynamic experiments at the laboratory scale, because there are hundreds of $A E$ events generated within a few hundred microseconds in one dynamic test. Therefore, moment tensor analysis is rarely applied in rock dynamic tests with laboratory scale. In this paper, AE and moment tensor simulations with the discrete element method (DEM) are introduced to analyze the microscopic failure mechanism of rock under a dynamic Brazilian test. Comparing the simulation results of $A E$ and moment tensor analysis with the simulation results of micro-crack with DEM, the moment tensor discriminant method can obtain the mechanical mechanism and energy level of microcracks. Furthermore, $\mathrm{R}$, which is the ratio of isotropic and deviatoric components of the moment tensor, is used to analyze the AE source mechanism. The implosion, shear, and tensile of the AE source mechanism can better explain the evolution process of main axial crack and the shear failure zones of the Brazilian disc specimen under dynamic tensile simulation. These findings contribute to a better understanding of the microscopic failure mechanism of rock under a dynamic tensile test than the statistical types of micro-cracks based on break bonds with DEM.

Keywords: moment tensor, rock dynamics, microscopic mechanism, discrete element method, acoustic emission

\section{INTRODUCTION}

Dynamic tensile failure is a main mode of rock failure in deep underground engineering projects [1, 2]. The microscopic failure mechanism of this failure mode is vital for dynamic disaster warning. It is important and necessary to study the micromechanical mechanism of rock dynamic tensile failure [3]. Moment tensor inversion is a very well-known method used to analyze failure mechanisms $[4,5]$. However, an acoustic emission (AE) event cannot be accurately distinguished in rock dynamic experiments at laboratory scale. The sampling rate of $\mathrm{AE}$ or micro-seismic monitoring equipment is about $10 \mathrm{MHz}$. The time of one rock dynamic experiment with SHPB is about $250 \mu$ s [6]. There are 
hundreds of $\mathrm{AE}$ events generated in one rock dynamic test. Therefore, moment tensor analysis is rarely applied in rock dynamic tests with laboratory scale. DEM simulation is also widely used to study failure mechanisms [7, 8]. The bond between particles break and many broken bonds will lead to rock failure when the rock specimen is under force action in simulation, which is often used to analyze the meso-crack extension [9]. The type statistics of bond break is used to distinguish the rock dynamic failure type [10]. However, the rock dynamic experiment and simulation studies show that the micro-crack of rock materials is mainly of the tensile crack variety no matter what the macroscopic failure mode is [11]. Therefore, a wrong result may be found if the macroscopic failure pattern is directly judged by statistical micro-crack types [12].

Some scholars introduced AE simulation based on DEM. Then the theory of $\mathrm{AE}$ can be used to analyze the micromechanical steps of the rock failure process with simulation. Hazzard and Young defined the range of bond break interplay between each other according to the crack propagation speed, and recorded the kinetic energy release in the process of intergranular bond fracture. In a closely packed particle assembly, this kinetic energy manifests itself as a seismic wave that propagates out from the location of the bond breakage, similar to an AE in real rocks. This method was then used to simulate the AE source in the process of a granite compression experiment [13]. On the basis of these studies, Hazzard and Young proposed a method to simulate a moment tensor with DEM. Then it was used to simulate the $\mathrm{AE}$ and moment tensor analysis of the tunnel excavation process. Comparing with the actual monitoring results, it was found that the model generated many implosion events agreeing partially with the actual recorded seismicity [14]. Cai et al. established a coupled numerical method with the finite element method (FEM) and DEM to simulation AE at the Kannagawa underground powerhouse cavern in Japan [15]. Lisjak et al. used two-dimensional FEM-DEM coupling analysis to simulate the AE in brittle rocks [16]. Zhang and Zhang built a rock model with two prefabricated cracks by PFC. Then the moment tensor was simulated to analyze the compression failure process of this model. This study analyzed the crack generation mechanism by using the moment tensor solutions and the statistic of the types of bond break contained in an $\mathrm{AE}$ event. It was discovered that the main bond break model of an $\mathrm{AE}$ event is tensile, while the AE mechanism is compression [17]. Zhang and Zhang used the moment tensor to distinguish the nature of primary cracks and secondary cracks in a single flawcontained specimen based on the bonded-particle model [12, 18].

Previous studies mentioned above show that AE source simulation and moment tensor analysis have great advantages in studying rock fracture mechanisms. In this paper, we introduce this method of AE and moment tensor simulation based on PFC to analyze the micromechanical mechanism of the rock dynamic tensile failure process. Firstly, the model of SHPB for dynamic Brazil splits is established. Then, we introduce the theory of AE definition and moment tensor. Finally, the microscopic mechanism of macroscopic tensile crack generated in the middle and the shear zone at both ends of the Brazilian disk during the dynamic tensile failure process are analyzed by using the simulation results of $\mathrm{AE}$ and moment tensor.

\section{MODELING APPROACH}

\section{Brief Description of Discrete Element Method}

DEM was first proposed by Cundall in the 1970s [19, 20]. After years of development, it is now widely used in different fields. As a mature commercial software of DEM, PFC is often used to study the micro-fracture process of rock mass in the field of rock mechanics.

In PFC, the numerical models are respectively composed of particles with a certain density bonded by the contact. The particles are disks with a certain thickness in PFC2D. And in PFC3D, the particles are small spheres. Each particle can be translated and rotated, and the interaction between particles is simulated through contact. Particles only interact with neighboring particles. The relative displacement between particles is the basic variable, and its motion follows the classical motion equation. When a particle is subjected to an external force or constraint, it will generate forces and torques acting on neighboring particles. The acceleration of related particles can be obtained from Newton's second law. The velocity and displacement of particles and other parameters can be obtained through the time integral. The physical quantities of acceleration, velocity, displacement, and rotation angle of all particles at any time can be obtained through the repeated iterative cycle of time step.

\section{The Model of Split Hopkinson Pressure Bar for Dynamic Tension}

The model of SHPB for the dynamic tension test, established in this paper, consists of two materials. One is the SHPB bar and the other is the rock specimen. There are two methods to simulate the bars of SHPB using PFC, one is generated by an extrusion exclusion method. Firstly, particles are generated randomly in the area of the bars according to the set porosity and particle radius. Then the repulsive force is generated between the particles through repeated cycle calculation, and the randomly generated overlapping particles enter a state of close contact with each other under the action of repulsive force [21]. Another method is the regular arrangement method, which can be realized by generating the particles with same radius, orderly distributed in the bar region. Studies have shown that the bars generated by the regular arrangement method can greatly improve the generation speed. The stress wave propagates in the bar constituted of regularly arranged particles without attenuation and dispersion [22]. Therefore, we use the regular arrangement method to generate the incident bar and transmission bar in our paper. The contact model of the particles in the bars is a linear contact bond. The incident and transmitted bars are 1,250 and $750 \mathrm{~mm}$ long, respectively, with a diameter of $50 \mathrm{~mm}$.

The specimen in this model is generated by the extrusion exclusion method. The particles are randomly generated with 


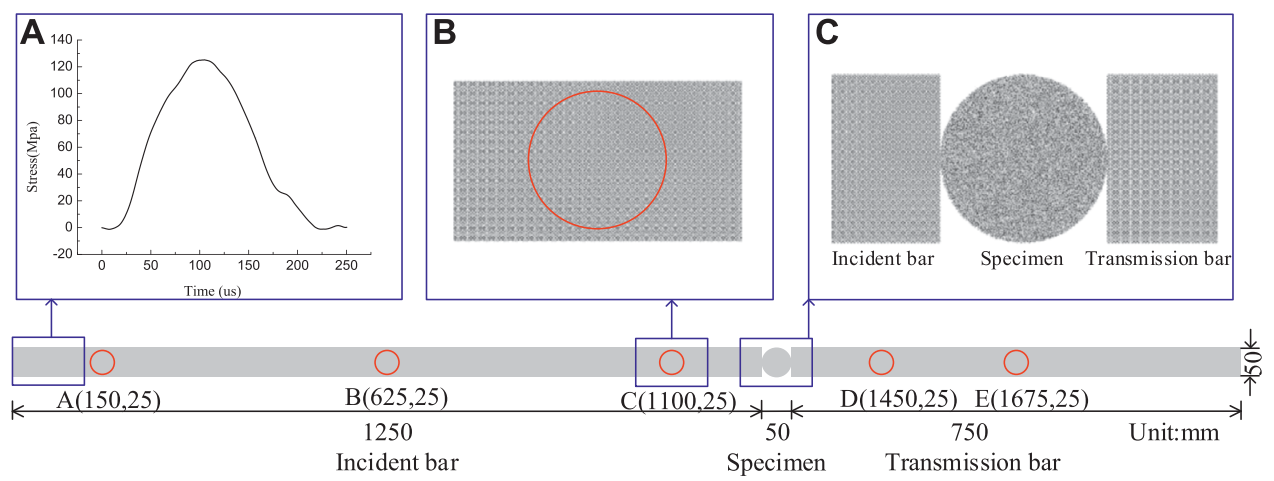

FIGURE 1 | The model of SHPB for dynamic tensile simulation. (A) The incident stress wave in simulation and experiment; (B) measure circles on the bars of this model; (C) the details of the specimen sandwiched between the incident and transmitted bars.

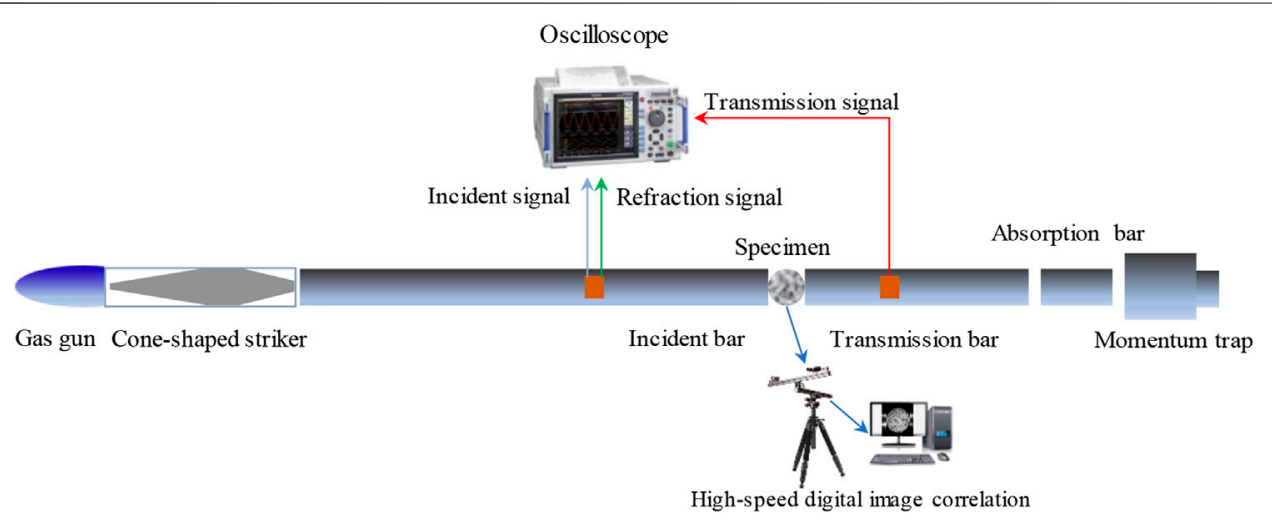

FIGURE 2 | SHPB, oscilloscope, and high-speed digital image correlation used in the rock dynamic tensile experiment.

specified porosity and radius in the specimen region. Then the repulsion force is generated between the originally overlapped particles through cyclic calculation, and finally the particle model with close contact is generated. The contact model of the particles in the specimen is a linear parallel bond. The model of SHPB for the dynamic tensile simulation is shown in Figure 1. The stress wave (Figure 1A) is loaded on the left end of the incident bar. Five measure circles (Figure 1B) are embedded in the incident and transmitted bars. Figure 1C contains the details of the specimen sandwiched between the incident and transmitted bars.

\section{Microscopic Parameter Determined in the Simulation}

To obtain microscopic parameters in the simulation, the dynamic tensile experiment of red sandstone is carried out using SHPB. SHPB, oscilloscope, and HS photography were used in this experiment as shown in Figure 2. The improved SHPB consists of a gas gun, a cone-shaped striker, an incident bar, a transmission bar, an absorption bar, and a momentum trap. All of the bars and the striker are made up of high strength $40 \mathrm{cr}$ alloy with an elastic modulus of $233 \mathrm{GPa}$, a density of $7,670 \mathrm{~kg} / \mathrm{m}^{3}$, a P wave velocity of $5,462 \mathrm{~m} / \mathrm{s}$, and a yield strength of $800 \mathrm{MPa}$ [23].

We use HS photography to obtain pictures during the failure process of the rock dynamic tensile test. The HS camera captured pictures in this experiment at a frequency of 79,161 frames/s with a resolution of $256 \times 256$ pixels. The HS camera uses an external trigger to start capturing images. When the voltage of strain gauge on the incident bar rises to $-34 \mathrm{mv}$, the oscilloscope and HS camera are simultaneously triggered to ensure time consistency. The specimen used in this experiment is red sandstone with a radius of $50 \mathrm{~mm}$ and a height of $30 \mathrm{~mm}$.

During the dynamic test, a longitudinal compressive wave (incident wave) is generated by the impact of a cone-shaped striker bar on the free end of the incident bar. Then this compressive wave (incident wave) propagates in the incident bar. When the compressive incident wave reaches the interfaces of bars and specimen, it is partly reflected (reflected wave), and the remainder passes through the rock specimen to the transmitted bar (transmitted wave). These three elastic stress pulses in the incident and transmitted bars are recorded with the strain gauges and denoted as the input strain pulse $\mathrm{I}(\mathrm{t})$, reflected strain pulse $R(t)$, and transmitted strain pulse $T(t)$, respectively 


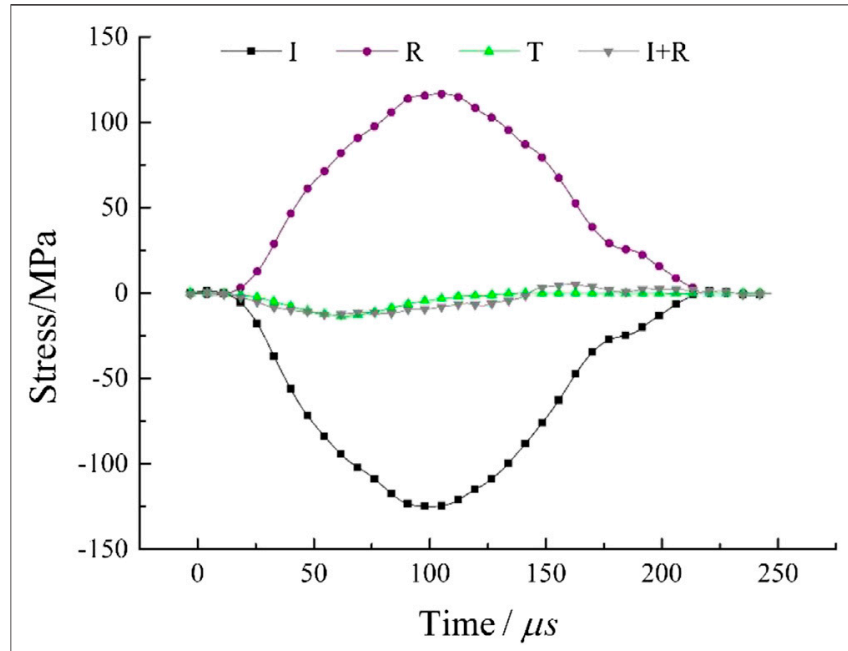

FIGURE 3 | Incident (I), reflected (R), transmitted (T), and incident + reflected $(I+R)$ stress wave of the dynamic tensile experiment.

[24]. The waveform data recorded by the oscilloscope are processed based on one dimensional stress wave theory [25, 26]. The results of incident stress wave, reflected stress wave, and transmitted stress wave are shown in Figure 3. The superposed waveform of the incident wave and the reflected wave is substantially the same as the transmitted wave near the peak, which verifies that this experiment satisfies the dynamic force balance.

We use the data of the incident wave in the dynamic test as the incident wave in the simulation. By adjusting the mesoscopic parameters in the simulation, the measured reflected wave and projected wave in the simulation are basically consistent with the experimental results, which ensures that the simulated dynamic tensile strength curve of red sandstone is basically consistent with the experimental results. The comparison results of the simulation and experimental waveforms are shown in Figure 4.

The microscopic and macroscopic parameters of the bars are shown in Table 1. The Young's modulus and density of the model corresponds to the experiment. The bond strength of the bar in this model is set extremely large to ensure that the bars will not deform during the impact process.

The specimen in this model is calibrated according to the dynamic tensile results of sandstone. The microscopic and macroscopic parameters of the specimen are shown in Table 2.

\section{Acoustic Emission Definition in Dynamic Tensile Simulation}

Studies have shown that, the bond break between contacted particles can simulate the micro-cracks in the simulation of rock with DEM [27]. Based on this, Young proposed that the break of a bond between particles can be used to simulate $\mathrm{AE}[8$, 9]. When bonds break, energy is released and AE locations and magnitudes can be calculated. Therefore, bonded particle models

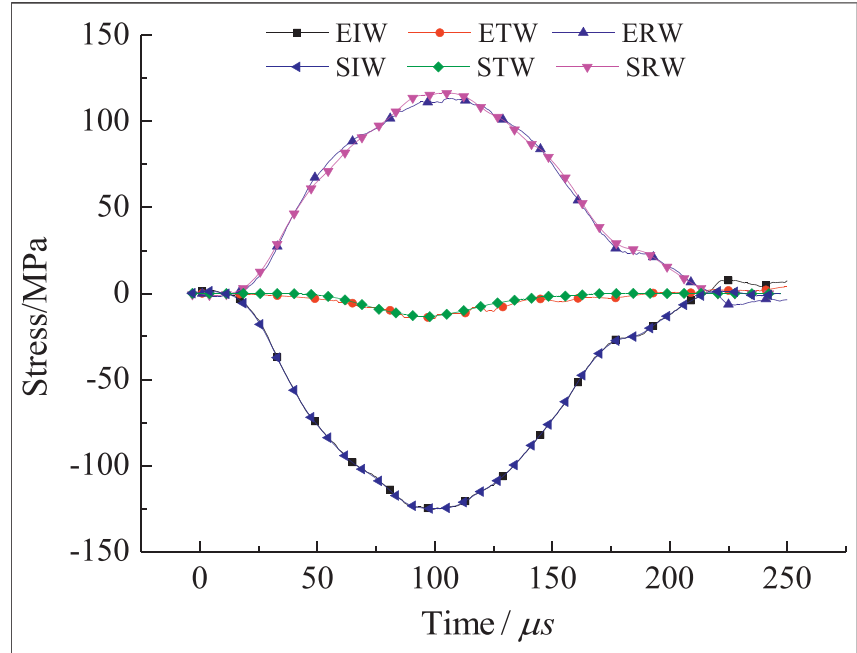

FIGURE 4 | The comparison of waveforms in experiment and simulation. The experimental incident wave (EIW) and the simulated incident wave (SIW) are identical. The experimental reflected wave (ERW) and the simulated reflected wave (SRW) as well as the experimental transmitted wave (ETW) and the simulated transmitted wave (STW) are also substantially similar.

provide a unique method to simulate $\mathrm{AE}$ [28]. Based on this, the $\mathrm{AE}$ definition in the dynamic tensile simulation will be introduced in this section.

When the incident wave propagates from the incident bar to the specimen, the bonds in the specimen begin to break under the action of the stress wave. This bond break is marked as the beginning of an AE. If each bond break is considered as an $\mathrm{AE}$ event, then the magnitudes of these $\mathrm{AE}$ events will be similar. This is not conformed to power-law distribution which is already a law of magnitude distribution recognized in seismology [29]. According to the characteristics of $\mathrm{AE}$ in rock mechanic experiments, bond breaks occurring close together in space and time are regarded as the same $\mathrm{AE}$ event in the simulation. This is similar with the actual AE monitoring, which distinguishes different AE events by setting peak definition time (PDT), hit definition time (HDT), and hit lockout time (HLT) of the AE signal. In the simulation, an $\mathrm{AE}$ event is determined by monitoring the bond break. The continuing AE event is determined by the number of calculating steps, which is 40 steps in this simulation. The restriction of an AE event calculating steps is verified by Hazzard and Damjanac [16]. The maximum area of an $\mathrm{AE}$ event is defined as 6 times the average particle radius. Figure 5 is an $\mathrm{AE}$ event generation process in the dynamic tensile simulation. Figure $\mathbf{5 A}$ is the beginning state of this AE event. Figure 5B is the end state of this AE event.

The magnitude of $\mathrm{AE}$ is an important parameter for $\mathrm{AE}$ evaluation. In the PFC simulation, AE energy is calculated by the differences of strain energy before and after the $\mathrm{AE}$ event generation [30]. The strain energy can be expressed as: 
TABLE 1 | The microscopic and macroscopic parameters of the bars.

Microscopic parameters

Particle

Radius (mm)

Density $\left(\mathrm{kg} / \mathrm{m}^{3}\right)$

Bond

Tensile strength (MPa)

Shear strength (MPa)
Macroscopic parameters

Steel

Model

Young's modulus (GPa)

Density $\left(\mathrm{kg} / \mathrm{m}^{3}\right)$
0.5

$1.05^{\star} 10^{5}$

$1.05^{\star} 10^{5}$

TABLE 2 | The microscopic and macroscopic parameters of the specimen.

Microscopic parameters

Particle

Radius ( $\mathrm{mm}$ )

Density $\left(\mathrm{kg} / \mathrm{m}^{3}\right)$

Young's modulus (GPa)

Stiffness ratio $\mathrm{kn} / \mathrm{ks}$

Friction coefficient

Bond

Radius multiplier

Young's modulus (GPa)

Stiffness ratio $\mathrm{kn} / \mathrm{ks}$

Tensile strength (MPa)

Frictional angle
Macroscopic parameters

Density $\left(\mathrm{kg} / \mathrm{m}^{3}\right)$

Dynamic tensile strength
Red sandstone

\section{2,337.5}

13.7

Model

$0.25-0.5$

2,350

27

2.0

0.577

\section{A}

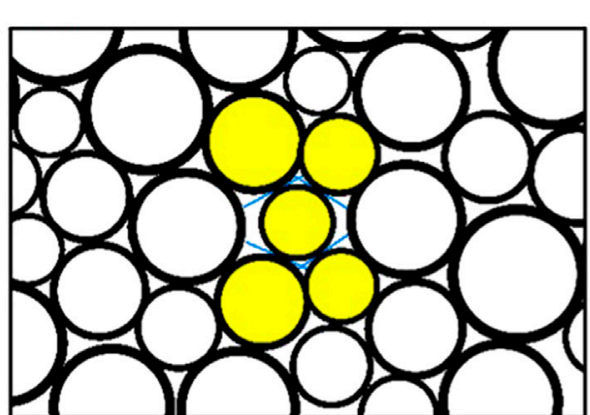

Tagged particles belonging to the current $\mathrm{AE}$

Bond between tagged particles belonging

to the current $\mathrm{AE}$
B

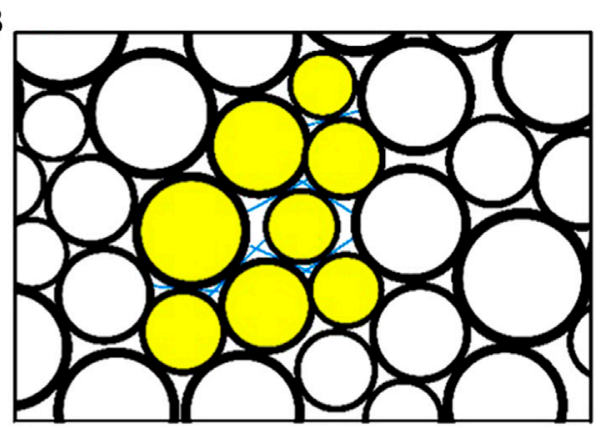

FIGURE $\mathbf{5}$ | An AE event generation process in this simulation. (A) is the start of an event and (B) is the finish state of this event

$$
E_{c}=\frac{1}{2}\left(\frac{\left|F^{n}\right|^{2}}{k^{n}}+\frac{\left|F^{s}\right|^{2}}{k^{s}}\right)
$$

where $F^{n}$ and $F^{s}$ are normal and shear forces of contact; $k_{n}$ and $k_{s}$ are contact normal stiffness and contact shear stiffness.

For each calculation step, the strain energy of all particles in the $\mathrm{AE}$ region, $E_{\mathrm{k}}$, is calculated, as:

$$
E_{k}=\sum E_{c}^{i}
$$

where $E_{c}^{i}$ is the strain energy of the $i$ contact in the AE region.

And the AE energy, $\Delta E_{\mathrm{k}}$, is equal to the final strain energy, $E_{k}^{f}$, minus the initial strain energy, $E_{k}^{0}$, in the $\mathrm{AE}$ region:

$$
\Delta E_{k}=E_{k}^{f}-E_{k}^{0}
$$

then the magnitude can be expressed as [31]:

$$
M_{e}=\frac{2}{3}\left(\log \Delta E_{k}^{\max }-4.8\right)
$$

\section{Moment Tensor Calculation in the Dynamic} Tensile Simulation

In seismology, a moment tensor is a mathematical representation of the movement on a fault during an earthquake, comprising 

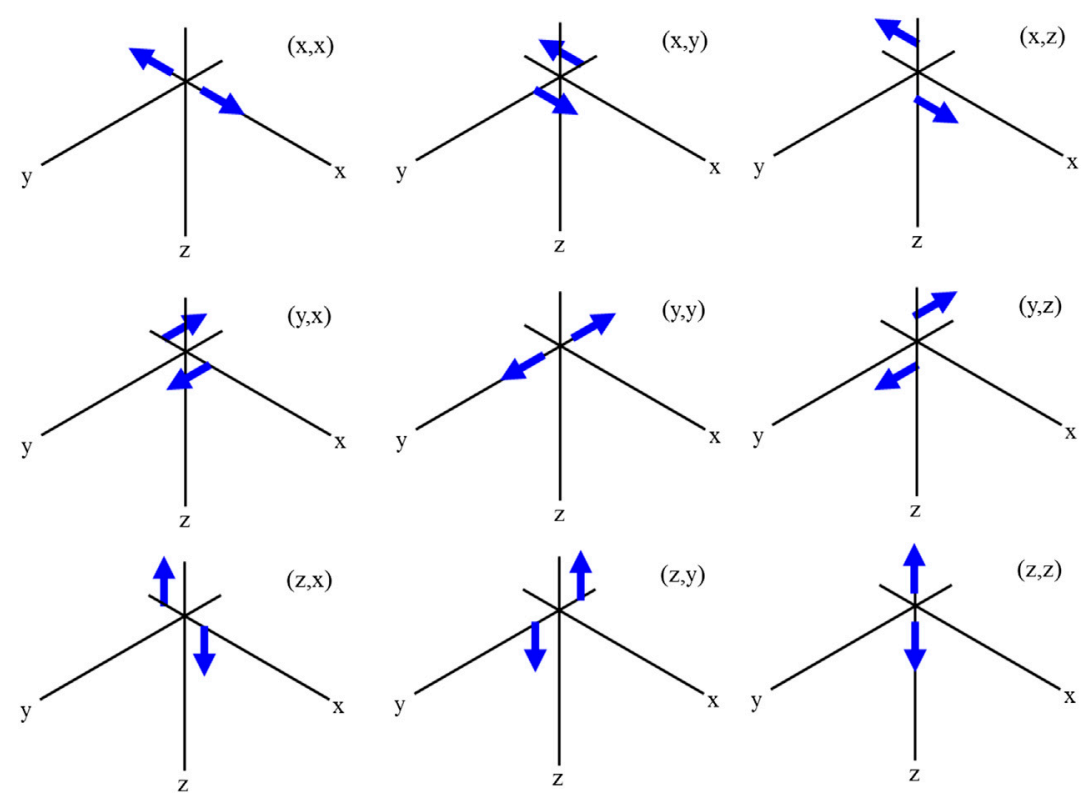

FIGURE 6 | The moment tensor comprising nine sets of two vectors.
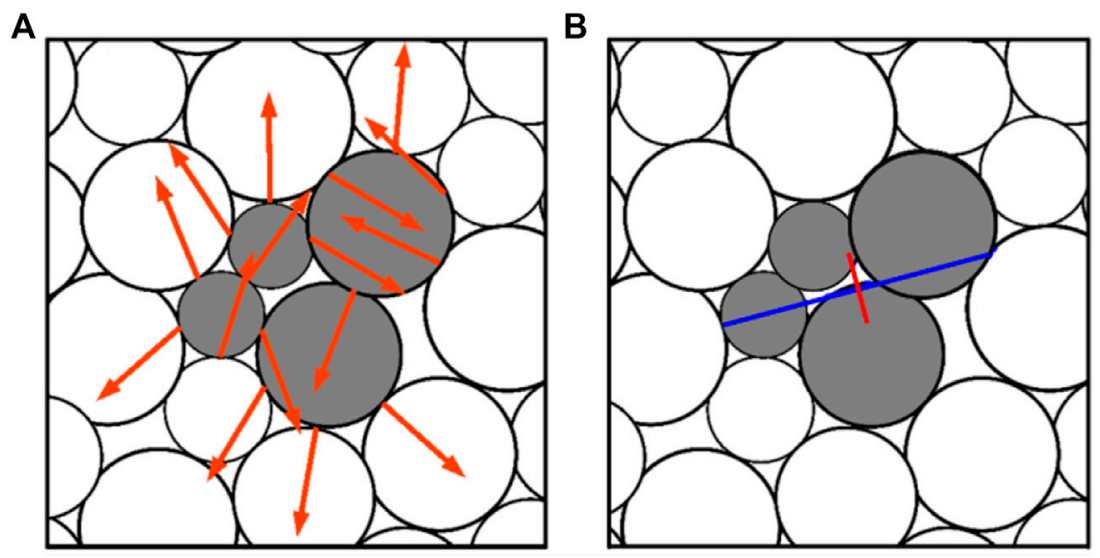

Tagged particles belonging to the current $\mathrm{AE}$

Contact forces belonging to the current $\mathrm{AE}$

Moment tensor of the current AE event

FIGURE 7 | The example of an AE event and its calculation moment tensor. (A) The contact force of all particles in an AE event. (B) The calculated moment tensor of this event. The length of these two lines represent the principal values of the moment tensor. The red line represents tensile and the blue line represents compression.

nine generalized couples, or nine sets of two vectors [32]. They are described in Figure 6. The tensor depends of the source strength and fault orientation.

In $2 \mathrm{D}$, it can be expression as follows:

$$
\mathrm{M}=\left[\begin{array}{ll}
M_{x x} & M_{x y} \\
M_{y x} & M_{y y}
\end{array}\right]
$$

PFC simulation can directly obtain the force state and displacement of all particles under the external force of the model. In $2 \mathrm{D}$, the contact force vector and the displacement vector between the contact point and the centroid of an $\mathrm{AE}$ event has components in two directions [14]. Then the moment tensor can be obtained based on the definition of $\mathrm{AE}$ in simulation. The detailed calculation process of a moment tensor is shown below: 
(1)

$101 \mu \mathrm{s}$
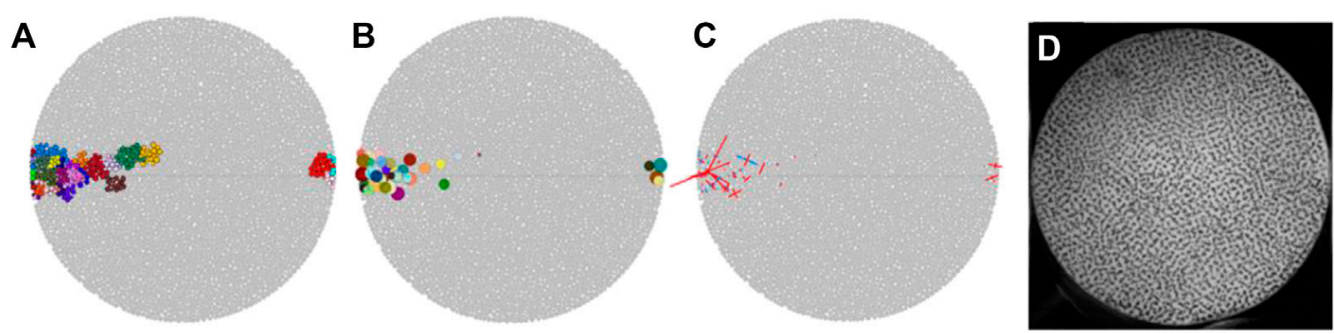

(2)

$113 \mu \mathrm{s}$
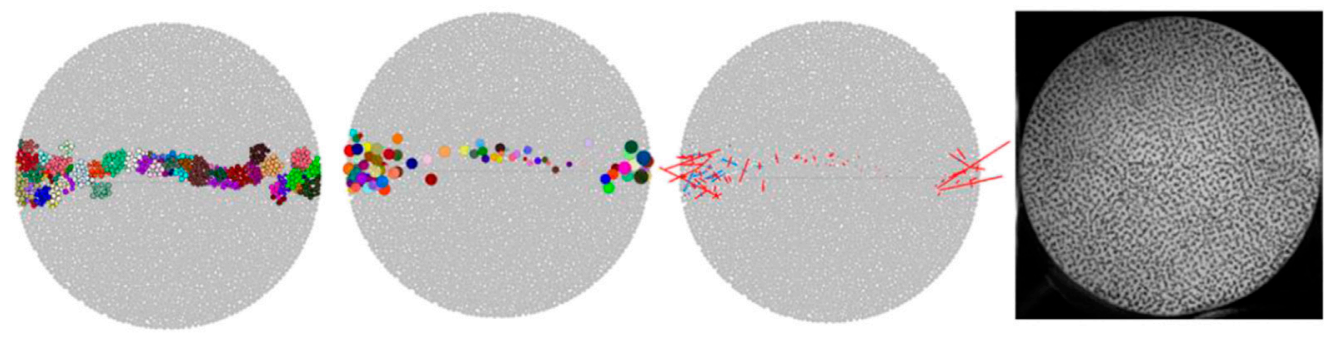

(3)

$125 \mu \mathrm{s}$
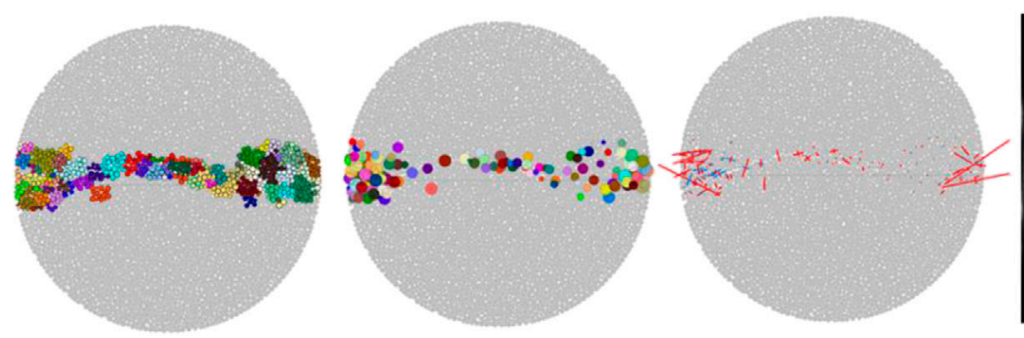

FIGURE 8| The results of AE location, moment tensor in simulation, and HS photography before and after the axial macro-crack generated. (A) is the AE location at different moments; (B) is the AE normalization diagram with the initial generating position of each AE event as the center of the circle and the AE energy level value as the radius; (C) is the results of the moment tensor; $(\mathbf{D})$ is the results of high speed photographs in the dynamic tensile experiment.

$$
M_{i j}=\sum_{S} \Delta F_{i} R_{j}
$$

where $\Delta F_{i}$ is the $i$ th component of the contact force change in an $\mathrm{AE}$ event. $R_{j}$ is the $j$ th component of the distance between the contact point and the barycenter of the $\mathrm{AE}$ event. In $2 \mathrm{D}$, there are two components of $F$ and $R, \mathrm{x}$ and $\mathrm{y} . S$ is the number of contacts in the area of an $\mathrm{AE}$ event.

Figure 7 is the example of an $\mathrm{AE}$ event and its moment tensor. The contact forces of this AE event are shown in Figure 7A. The four Gy particles in the middle represent an $\mathrm{AE}$ event. The red arrows indicate the contact forces on the particles of this $\mathrm{AE}$ event. The value and action point of these contact forces can be directly obtained from the PFC simulation. Then the moment tensor can be calculated by Eqs (5) and (6). The length of these two lines in Figure 7B represents the principle eigenvalues and eigenvectors of the matrix.

\section{RESULTS OF ACOUSTIC EMISSION AND MOMENT TENSOR SIMULATION DURING THE DYNAMIC TENSION FAILURE OF ROCK}

The rock dynamic tensile failure process is simulated by the SHPB model as established in the previous section. The AE and moment tensor of this failure process are calculated. The results of the moment tensor simulation and AE source mechanism are used to analyze the micro-mechanical mechanism of the rock dynamic tensile process. Studies show that the dynamic tensile process can be divided into two parts for analysis. One part analyzes the micro-mechanical mechanism of the main axial crack which is parallel to the impact direction and divides the specimen into two pieces. The other part analyzes the micro-mechanical mechanism of the shear failure zones that occur at the contact points of the Brazilian disk (BD) specimen [33]. These two parts will be analyzed separately in the following part.

\section{Acoustic Emission and Moment Tensor of the Main Axial Crack Parallel to the Impact Direction}

Figure 8 is the results of the $\mathrm{AE}$ and moment tensor before and after the axial macro-crack generated in the rock dynamic tensile simulation. Figure $\mathbf{8 A}$ shows the $\mathrm{AE}$ events as expressed by marked particles. Figure $\mathbf{8 B}$ is the normalized AE location of the left picture. Each AE event is expressed with a circle. The center of the circle is the barycenter of this AE event, and the radius is the value of the normalized AE event energy magnitude. Therefore, the middle picture can intuitively show the position and 
(1)

$149 \mu \mathrm{s}$
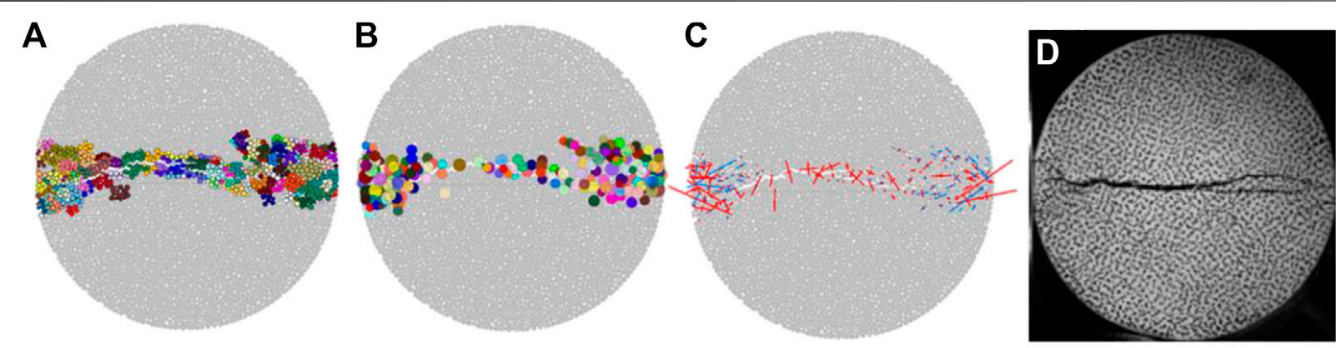

(2)

$161 \mu \mathrm{s}$
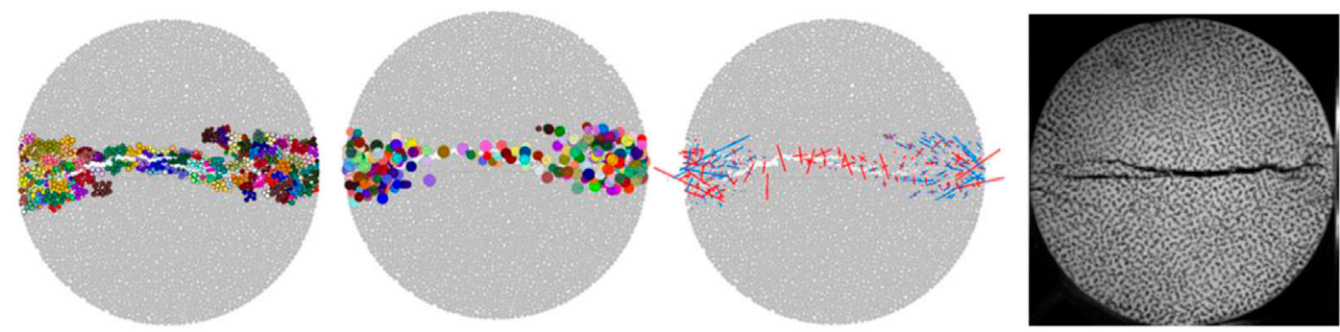

(3)

$173 \mu \mathrm{s}$
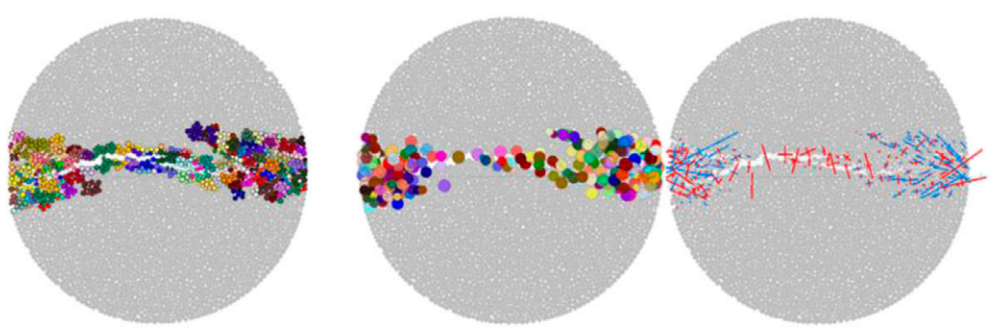

FIGURE 9| The results of AE location, moment tensor in simulation, and HS photography before and after the shear failure zones. (A)-(D) of Figure $\mathbf{9}$ correspond to the same figure values as Figure 8.

magnitude of each AE event. Figure 8C shows the results of the moment tensor simulation. The position of each moment tensor is the barycentric coordinates of an $\mathrm{AE}$ event. Figure 8D shows the results of HS photography.

Figures 8(1)-(3) are the results of the simulation and HS photography at $101 \mu \mathrm{s}, 113 \mu \mathrm{s}$, and $125 \mu \mathrm{s}$, respectively. At $101 \mu \mathrm{s}$, the AE events distribute mainly in the two ends of the specimen, the cumulative number of these $\mathrm{AE}$ events is 76 with a magnitude range of -4.3 to -0.76 . There is no macro-crack formation in the experiment from the results of the HS photographic image. Figure 8(2)B shows that most of these $\mathrm{AE}$ events are generated at middle of the specimen. The cumulative number of $\mathrm{AE}$ events is 116. The number of new $\mathrm{AE}$ events generated in this period is 40 with a magnitude range of -2.11 to -0.75 . Figure 8(2)C shows the moment tensor of each $\mathrm{AE}$ event. Figure $8(2) \mathrm{D}$ shows a macroscopic crack initiation at the middle of the specimen HS photographic image. At $125 \mu \mathrm{s}$, there are 41 new $\mathrm{AE}$ events generated with a magnitude range of -2.84 to -1.59 . In the meantime, this initiation crack from the initiation position extends to the ends of the specimen in the experiment. From the results of the AE location and HS photography of these three stages, it can be found that macroscopic cracks occur only when the number of $\mathrm{AE}$ is enough or the $\mathrm{AE}$ magnitude reaches a certain value.

\section{Acoustic Emission and Moment Tensor of the Shear Failure Zones}

Studies show that there are shear failure zones that occur at the contact points of the $\mathrm{BD}$ specimen, which become more significant with an increase of loading rate, in the dynamic tensile experiment. The shear failure zone is a result of secondary fractures due to further compression between the bar and the cracked disc as demonstrated by the high-speed camera snapshots. In this section, the simulation results of the $\mathrm{AE}$ and moment tensor are used to analyze the generation process of the shear failure zones.

Figure 9 expresses the shear failure zones formation. Figures 9(1)-(3) show this new crack initiation, extension, and formation at $149 \mu \mathrm{s}, 161 \mu \mathrm{s}$, and $173 \mu \mathrm{s}$, respectively. At 149 , the new AE event generated at the ends of the specimen coincides with the results of the HS photographic image. There are 48 new $\mathrm{AE}$ events with a magnitude ranging from -3.25 to -1.08 . At $161 \mu \mathrm{s}$, most of the new $\mathrm{AE}$ events continue to expand along the direction of the crack formed in the previous period. There are 23 new AE events with a magnitude of -2.6 to -1.27 in this period. The number of new $\mathrm{AE}$ events generated from 161 to $173 \mu$ s is 16 and the magnitude ranges from -2.14 to -0.89 . 
From the crack development process of the HS photography results and the corresponding AE simulation results in Figures 8 and $\mathbf{9}$, it can be concluded that the $\mathrm{AE}$ simulation in the rock dynamic tensile experiment is feasible. The simulation results of the AE location are consistent with the location of crack generation obtained by HS photography. The moment tensor simulation can explain the generation mechanism of the AE events. The microscopic failure mechanism of rock under a dynamic tensile test will be analyzed with the generation mechanism of $\mathrm{AE}$ events in the next section.

\section{DISCUSSION}

The results of $\mathrm{AE}$ and moment tensor simulation have shown that they can be used to analyze the dynamic tensile failure process. In this section, the AE source mechanism is calculated based on the simulation results of the AE location and moment tensor in order to analyze the micromechanical mechanism of the rock dynamic tensile failure process. Firstly, the calculation method of the AE source mechanism is described. Then, we compare the results of the discrete fracture network (DFN) obtained by the PFC to the results of the $\mathrm{AE}$ source mechanism.

\section{The Calculation Method of the Acoustic Emission Source Mechanism}

AE source mechanism analysis is an important method to study the rock crack propagation mechanism and rock failure mechanism $[34,35]$. Based on the simulation results of the $\mathrm{AE}$ location and moment tensor, the AE source mechanism in the sandstone dynamic tensile simulation is analyzed in this section. According to the calculation method of the moment tensor in the rock dynamic tensile in Moment Tensor Calculation in the Dynamic Tensile Simulation, the moment tensor of the AE source at different moments is calculated and represented by a vector diagram.

The ratio $\mathrm{R}$ of the isotropic and deviatoric components of the moment tensor can be used to analyze the mechanical mechanism of each AE source, which was first proposed by Feignier and Young [32]. Zhang and Zhang [11] used this method to analyze the crack nature in the bridge region of two pre-existing flaws under compressive loading. In $2 \mathrm{D}$, the ratio is expressed as follow:

$$
R=\frac{\operatorname{tr}(M) \times 100}{\left(|\operatorname{tr}(M)|+\sum_{i=1}^{i}\left|m_{i}^{*}\right|\right)}
$$

where $\operatorname{tr}(\mathrm{M})=\left(\mathrm{m}_{1}+\mathrm{m}_{2}\right), \mathrm{m}_{\mathrm{i}}$ and $m_{i}^{*}(\mathrm{i}=1,2)$ are the eigenvalue and partial eigenvalues of matrix $M$, respectively.

$$
m_{i}^{*}=m_{i}-\operatorname{tr}(M) / 2
$$

The value of $\mathrm{R}$ ranges from -100 to 100 . The ratio $\mathrm{R}$ and corresponding AE source mechanism are shown in Table 3.

\section{Microscopic Mechanism Analysis of the Rock Failure Process Under a Dynamic Brazilian Test}

The value of $\mathrm{R}$ is calculated based on the moment tensor to analyze the AE source mechanism. AE source mechanisms can describe how the AE event is generated according to the position change of $\mathrm{AE}$ event formation relative to the initial position. Implosion is one of the AE source mechanisms, which means that this $\mathrm{AE}$ event is generated by extrusion. Therefore, the AE source mechanisms are used to analyze the microscopic mechanism.

Figure $\mathbf{1 0}$ is the microscopic mechanism of the generation process of main axial crack. Figure 10A is the results of DFN obtained by PFC. The blue lines are micro-shear cracks, and the red lines are micro-tensile cracks. In the user manual of PFC, the DFN is defined as a collection of fractures, which is often used to analyze failure type in rock mechanic simulations. A fracture will come out when a bond between two particles breaks. DFNs consist of two types: tensile fractures and shear fractures [36]. We use the results of DFN to obtain the micro-cracks. Then the statistics of micro-cracks are used to analyze mechanical mechanism of macro-crack. There are mainly micro-tensile cracks and a few micro-shear cracks in the generation process of main axial crack. Figure 10B is the AE source mechanism results of the main axial crack distinguished by the ratio $\mathrm{R}$ in the dynamic tensile simulation. The red box, blue triangle, and green circle show that the AE mechanism is tensile, implosion, and shear, respectively. The crack model in the center of the specimen is tensile in the process of the axial crack generation. At the ends of specimen, the crack model is mainly tensile in the initial stage. Then some shear cracks occurred. When the axial crack completely formed, the AE source mechanism models are mainly tensile, which is same with the results of the DFN fracture.

Figure 11 is the statistical results of Figure 10. Figure $11 \mathrm{~A}$ is the number of different crack types increased from 100 to $126 \mu \mathrm{s}$ obtained by PFC simulation. The tensile micro-cracks continued to increase, and no new shear micro-cracks appeared based on PFC simulation. Figure 11B is the number of different types of AE source mechanisms increased from 100 to $126 \mu$ s obtained by the value of $\mathrm{R}$. The three types of AE source mechanisms all increase. The tensile fracture mechanism increases the most. Therefore, the fracture mechanism of axial crack in the middle of the specimen is tensile, which can be both obtained by the PFC simulation or AE source mechanisms.

Figure 12 is the microscopic mechanism of the shear zones generation in the ends of specimen. Figure 12A is the DFN fracture obtained by the PFC. The red lines represent the bond break mode between two particles, tensile crack. The blue lines represent the bond break mode, shear crack. Figure 12B is the results of the crack model obtained by the value $\mathrm{R}$ based on moment tensor simulation. The red box, blue triangle, and green circle show that the $\mathrm{AE}$ mechanism is tensile, implosion, and shear, respectively.

The results of the shear zone on both sides of the specimen in simulation are consistent in rock dynamic experiments of the existing research [37]. 
TABLE 3 | The ratio $R$ and corresponding AE source mechanism.

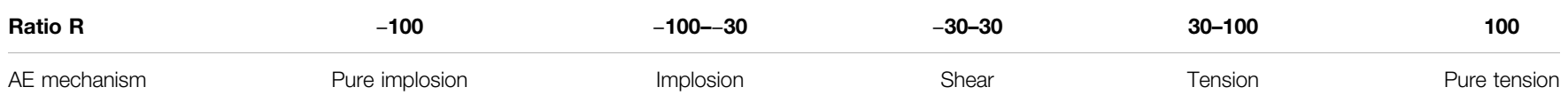
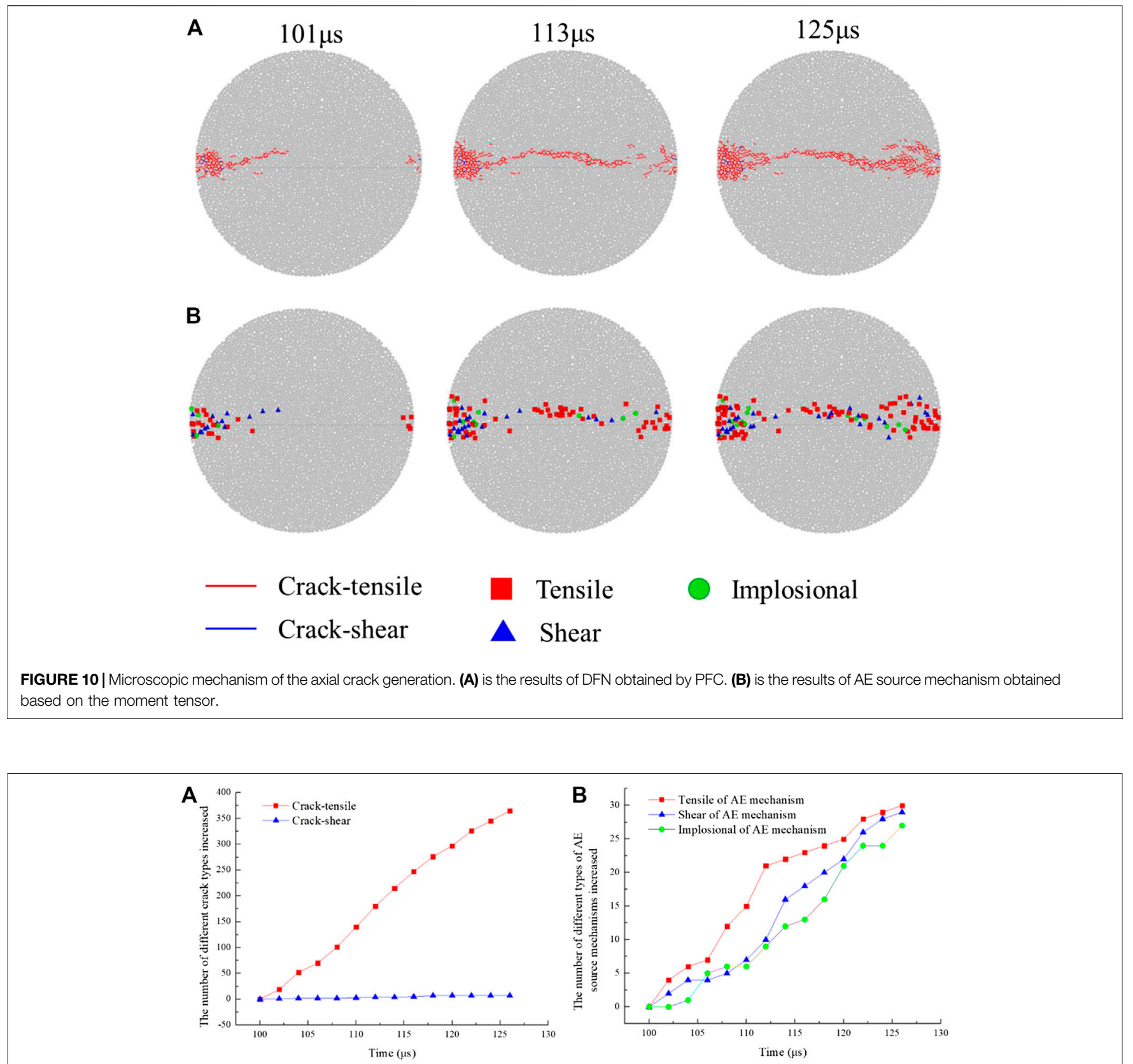

FIGURE 11 | The new increased micro-crack from 100 to $126 \mu$ s. (A) is the number of different crack types increased from 100 to $126 \mu$ s. (B) is the number of different types of $A E$ source mechanisms increased from 100 to $126 \mu$ s.

Figure $\mathbf{1 3}$ is the statistical results of Figure 12. Figure 13A is the number of different crack types increased from 148 to $173 \mu \mathrm{s}$ obtained by PFC simulation. The tensile micro-cracks continued to increase from 148 to $161 \mu$ s. Then it stays stable from 161 to
$173 \mu$ s, between which time the shear zones are formed. This phenomenon coincides with the HS photograph in Figure 7. There are no new shear micro-cracks based on the PFC simulation. Figure 13B is the number of different types of $\mathrm{AE}$ 

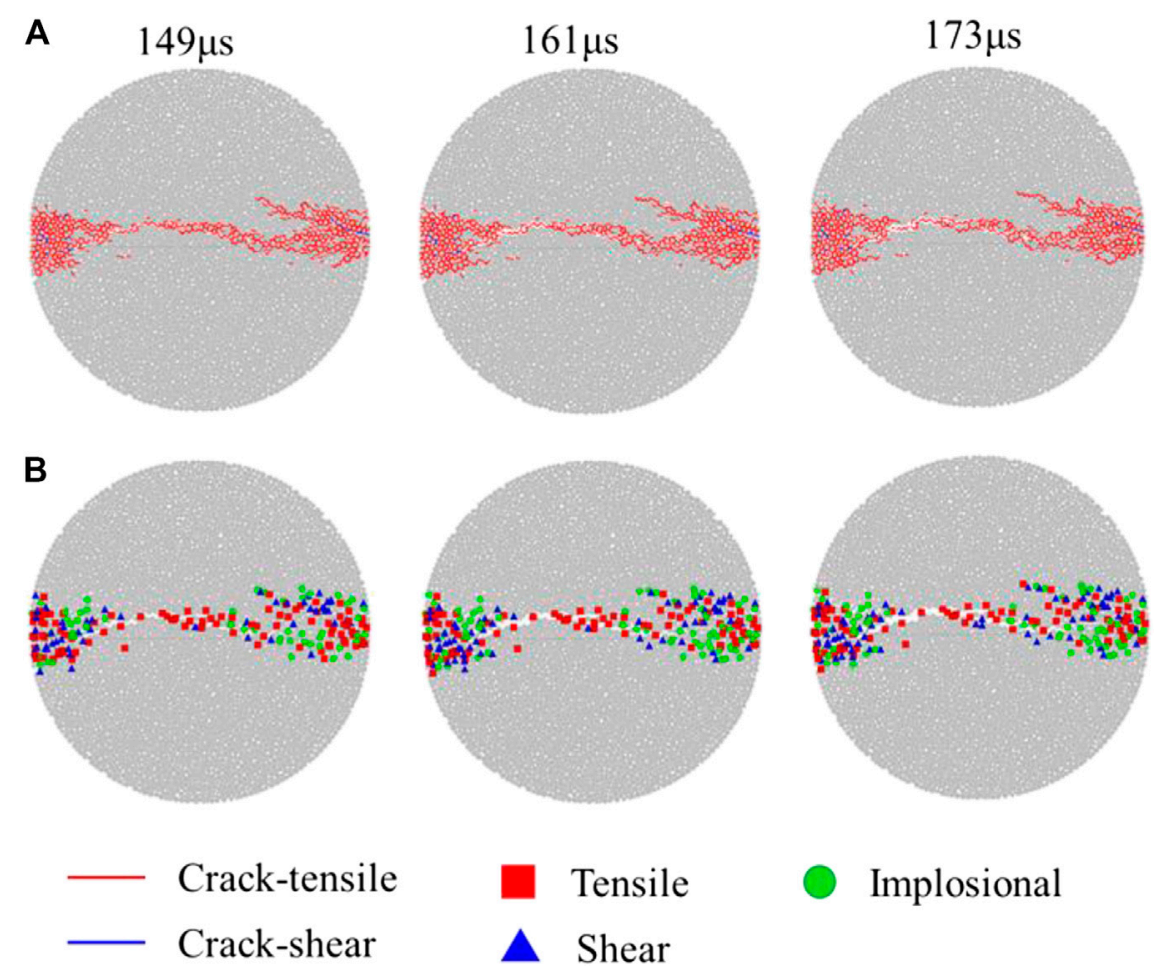

FIGURE 12 | Microscopic mechanism of the shear zones generation in the ends of specimen. (A) is the DFN fracture obtained by the PFC. (B) is the results of the AE source mechanism obtained based on the moment tensor.
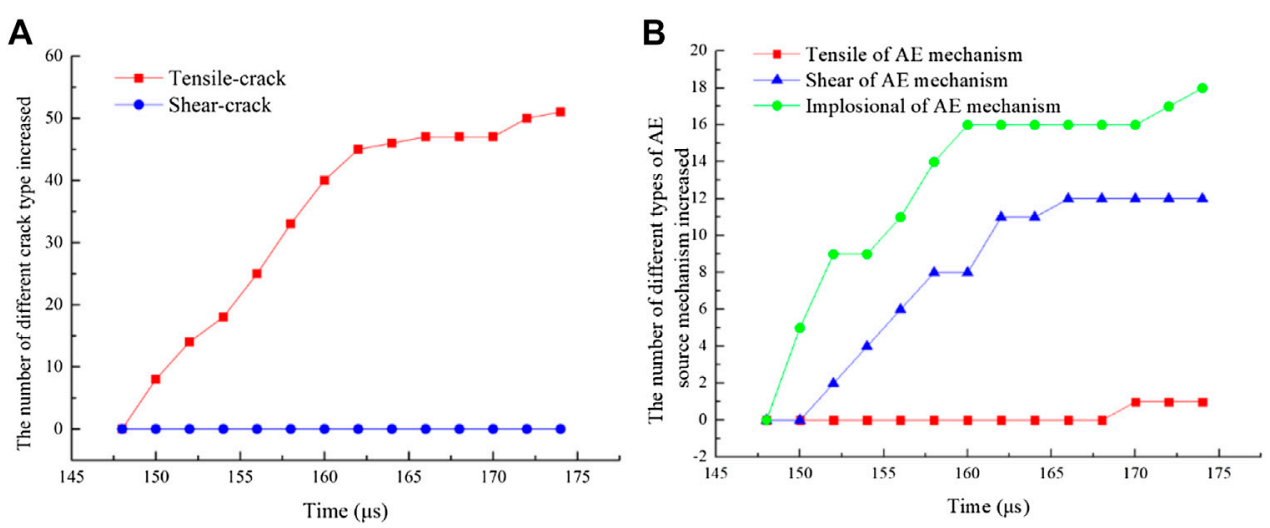

FIGURE 13 | The statistical results of different types of micro-crack. (A) is the number of different crack types increased from 148 to $173 \mu$ s obtained by PFC. (B) is the number of different types of AE source mechanisms increased from 148 to $173 \mu \mathrm{s}$.

source mechanisms increased from 148 to $173 \mu$ s obtained by the value of $\mathrm{R}$. The implosion and shear of the AE source mechanisms both increase from 148 to $161 \mu \mathrm{s}$. The number of implosion fracture mechanisms is the highest, which can be explained by the fact that the shear zones at both ends of the dynamic Brazil split specimen are formed by secondary loading. Comparing Figures 13A and Figure 13B, the fracture mechanism of the shear zones at the ends of the specimen obtained by the PFC simulation or AE source mechanisms are different. The statistical result of different crack types obtained by PFC shows that the fracture mechanism is tensile, which does not coincide with the HS photograph in Figure 8.

Figure 14A is the cumulative counts of different crack types obtained by bond break with the PFC simulation. The results 

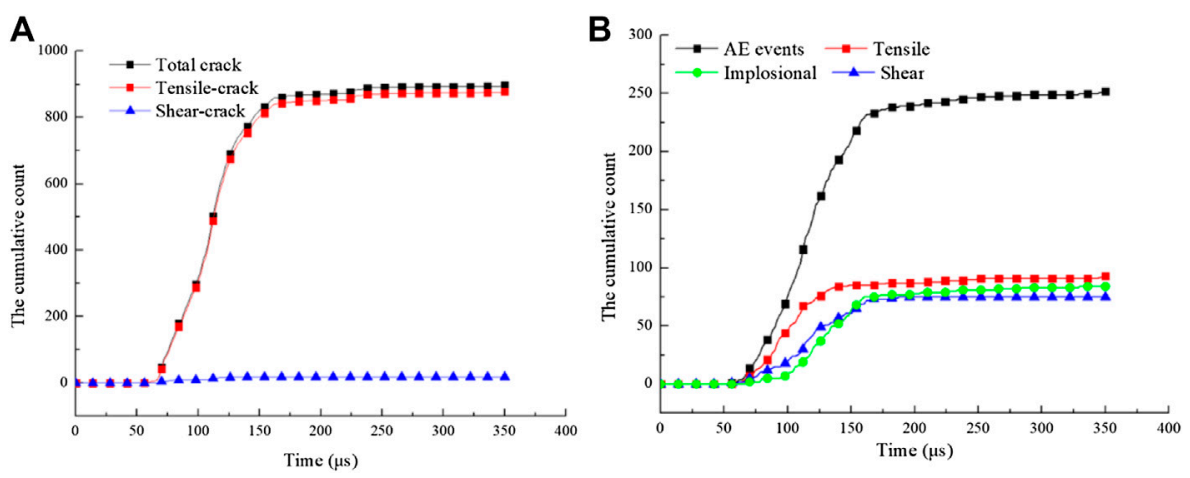

FIGURE 14 | The cumulative counts of different types of micro-crack. (A) is the cumulative counts of different crack types obtained by PFC. (B) is the cumulative counts of $A E$ events and three kinds of $A E$ source mechanism in the simulation.
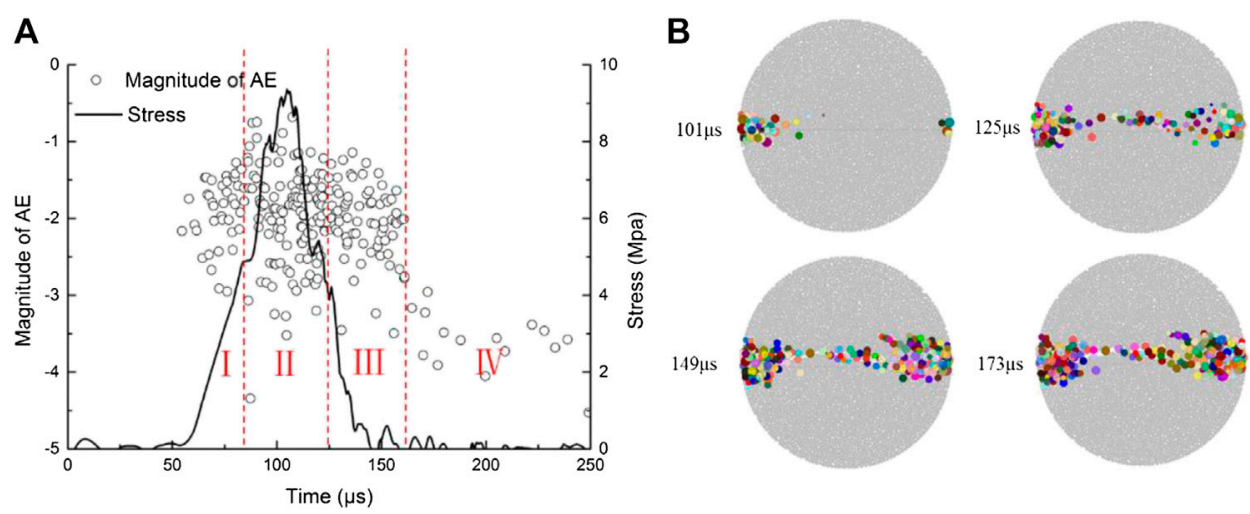

FIGURE 15 | (A) The magnitude of AE and stress on rock changing with time.

(B) The AE location in this simulation.

show that the micro-mechanical mechanisms are tensile in all the failure processes. Therefore, we can confirm the macromechanical mechanisms of this dynamic test as tensile.

The number of $\mathrm{AE}$ events and three kinds of $\mathrm{AE}$ source mechanism (tensile, implosion, and shear) during the period from the initiation of micro-cracks to the formation of macroscopic cracks (no more new cracks generation) in the specimen are counted. These four cumulative counts are shown in Figure 14B. The cumulative counts of AE start to grow rapidly at $75 \mu \mathrm{s}$. and reach a stable value at about $175 \mu \mathrm{s}$. The cumulative counts of tension start to grow rapidly at $75 \mu \mathrm{s}$ and reach a stable value at about $150 \mu$ s. The cumulative counts of implosion and shear start to grow rapidly at about $100 \mu$ s and reach a stable value at about $175 \mu$ s. The cumulative count of implosion and shear have an intersection point at about $150 \mu \mathrm{s}$. Before this point, the micro-mechanical mechanisms of the shear zones are mainly shear. After this point, the shear zone has been basically formed. The two ends of the specimen continue to be squeezed, the cumulative count of implosion becomes more than the shear.

Comparing with the results of the HS photograph in Acoustic Emission and Moment Tensor of the Main Axial Crack Parallel to the Impact Direction and Acoustic Emission and Moment Tensor of the Shear Failure Zones, the macro-mechanical mechanisms of the first macro-crack in the middle of the rock specimen is tensile. The macro-mechanical mechanisms of the other macro-crack in the two ends of the rock specimen are shear. The same results can be obtained by the simulation of the $\mathrm{AE}$ and moment tensor. However, the results of DFN with PFC can only explain the macro-mechanical mechanisms of the macro-crack generated in the middle of rock specimen in this dynamic test. Previous studies have also shown that the mechanical mechanisms of an AE event with moment tensor simulation are different with the result of DFN with PFC $[14,15]$.

\section{Relationship Between AE Magnitude and Failure Process}

Figure 15A shows that the failure process of rock under a dynamic Brazilian test can be divided into four stages according to magnitude and the stress on rock. Figure 15B shows the positions of these $\mathrm{AE}$ events. Before $101 \mu \mathrm{s}$, an $\mathrm{AE}$ event is mainly generated at the two ends of specimen. Magnitudes of these AE events are relatively small. There is 
no macro-crack generated in this phase. AE events with high magnitude mainly occur in the second phase. The macro-crack in the center of the specimen is also generated in this phase. The magnitude of AE generated in the third stage is slightly lower than that in the previous stage, and the positions generated are at both ends of the specimen which is the same as the first phase. The superposition of AE events in these two phases led to macrocrack. Therefore, we can confirm that the number and energy magnitude of AE events both affect the prediction of macro-crack generation during the failure process of a dynamic Brazilian test. The macro-crack in the center of the rock specimen is accompanied by $\mathrm{AE}$ events with a larger energy magnitude, while the macro-crack in the shear areas at both ends is accompanied by the accumulation of more AE events.

\section{CONCLUSIONS}

In order to analyze the microscopic mechanism of rock under a dynamic Brazilian test, an AE source and AE source moment tensor are simulated with $\mathrm{PFC}$ in this paper. The dynamic indirect tensile experiment of red sandstone with SHPB is conducted. HS photography is used to obtain the macroscopic failure process of the rock specimen. The simulated AE counts, different kinds of $\mathrm{AE}$ sources mechanism solutions, and $b$ values are counted and discussed. The simulation results of rock under a dynamic Brazilian test with PFC are also compared with the results of HS photography. The conclusions are as follows.

(1) The simulation of an AE source and AE moment tensor are feasible in analyzing the microscopic mechanism of dynamic tensile simulation in rock dynamics. The results of $\mathrm{AE}$ simulation can be used to analysis the micro-crack propagation process, which is consistent with macroscopic cracking shown by HS photography. The AE magnitude and moment magnitude can be used to distinguish key events in the rock failure process. The AE mechanism obtained by the value of $R$ verifies that they can be used to analyze the generation mechanism of micro-crack and rock dynamic failure.

\section{REFERENCES}

1. Zhu WC, Niu LL, Li SH, Xu ZH. Dynamic Brazilian test of rock under intermediate strain rate: pendulum hammer-driven SHPB test and numerical simulation. Rock Mech Rock Eng (2015) 48(5):1867-81. doi:10. 1007/s00603-014-0677-7

2. Ai D, Zhao Y, Xie B, Li C. Experimental study of fracture characterizations of rocks under dynamic tension test with image processing. Shock Vib (2019) 2019: 1-14. doi:10.1155/2019/6352609

3. $\mathrm{Wu} \mathrm{Z}, \mathrm{Xu} \mathrm{L}$, Liu Q. Numerical investigation of rock heterogeneity effect on rock dynamic strength and failure process using cohesive fracture model. Eng Geol (2015) 197:198-210. doi:10.1016/j.enggeo.2015.08.028

4. Zhao JS, Feng XT, Jiang Q, Zhou Y-Y. Microseismicity monitoring and failure mechanism analysis of rock masses with weak interlayer zone in underground intersecting chambers: a case study from the Baihetan Hydropower Station, China. Eng Geol (2018) 245:44-60. doi:10.1016/j. enggeo.2018.08.006
(2) The results of the AE mechanism can explain the micromechanical mechanism of the main axial crack, which is parallel to the impact direction and divides the specimen into two pieces, and the shear failure zones which occur at the contact points of the $\mathrm{BD}$ specimen. The micromechanical mechanisms of the main axial crack are tensile. The micro-mechanical mechanisms of the shear zones are mainly tensile before the macro-crack generated in the two ends of the specimen. When the macro-crack is generated in the two ends of the specimen, the cumulative count of implosion and shear have an intersection point. Before this point, the micro-mechanical mechanisms of the shear zones are mainly shear. After this point, the shear zone has been basically formed. The two ends of the specimen continue to be squeezed, the cumulative count of implosion becomes more than the shear.

\section{DATA AVAILABILITY STATEMENT}

The raw data supporting the conclusions of this article will be made available by the authors, without undue reservation.

\section{AUTHOR CONTRIBUTIONS}

JZ and YZ conceived the idea, performed the data analyses, and wrote the manuscript. $\mathrm{ZZ}$ and CL contributed significantly to analysis and manuscript preparation and helped to perform the analysis with constructive discussions. All authors contributed to the article and approved the submitted version.

\section{FUNDING}

The authors gratefully acknowledge financial support from the National Natural Science Foundation of China (41772313) and the Fundamental Research Funds for the Central Universities of Central South University (2019zzts308).

5. Chong Z, Li X, Hou P, Chen X, Wu Y. Moment tensor analysis of transversely isotropic shale based on the discrete element method. Int J Min Sci Technol (2017) 27(3):507-15. doi:10.1016/j.ijmst.2017.03.023

6. Cai X, Zhou ZL, Zang HZ, Song Z. Water saturation effects on dynamic behavior and microstructure damage of sandstone: phenomena and mechanisms. Eng Geol (2020) 276:105760. doi:10.1016/j.enggeo.2020.105760

7. Pei P, Dai F, Liu Y, Wei M. Dynamic tensile behavior of rocks under static pretension using the flattened Brazilian disc method. Int J Rock Mech Min Sci (2020) 126:104208. doi:10.1016/j.ijrmms.2019.104208

8. Imani M, Nejati HR, Goshtasbi K. Dynamic response and failure mechanism of Brazilian disk specimens at high strain rate. Soil Dynam Earthq Eng (2017) 100: 261-9. doi:10.1016/j.soildyn.2017.06.007

9. Wong LNY and Einstein HH. Crack coalescence in molded gypsum and carrara marble: Part 1. Macroscopic observations and interpretation. Rock Mech Rock Eng (2009) 42(3):475-511. doi:10.1007/s00603-008-0002-4

10. Zeng W, Yang SQ, Tian WL. Experimental and numerical investigation of brittle sandstone specimens containing different shapes of holes under uniaxial compression. Eng Fract Mech (2018) 200:430-50. doi:10.1016/j.engfracmech.2018.08.016 
11. Wu BB, Xia KW, Chen R. "Dynamic tensile failure of rocks subjected to simulated in situ stresses", in International Congress on rock mechanics (2015).

12. Zhang $\mathrm{Q}$ and Zhang XP. The crack nature analysis of primary and secondary cracks: a numerical study based on moment tensors. Eng Fract Mech (2019) 210:70-83. doi:10.1016/j.engfracmech.2018.05.006

13. Hazzard JF and Young RP. Simulating acoustic emissions in bonded-particle models of rock. Int J Rock Mech Min Sci (2000) 37(5):867-72. doi:10.1016/ S1365-1609(00)00017-4

14. Hazzard JF and Young RP. Moment tensors and micromechanical models. Tectonophysics (2002) 356(1):181-97. doi:10.1016/S1365-1609(00)00017-4

15. Cai M, Kaiser PK, Morioka H, Minami M, Maejima T, Tasaka Y, et al. FLAC/ PFC coupled numerical simulation of $\mathrm{AE}$ in large-scale underground excavations. Int J Rock Mech Min Sci (2007) 44(4):550-64. doi:10.1016/j. ijrmms.2006.09.013

16. Lisjak A, Liu Q, Zhao Q, Mahabadi OK, Grasselli G. Numerical simulation of acoustic emission in brittle rocks by two-dimensional finite-discrete element analysis. Geophys J Int (2013) 195(1):423-43. doi:10.1093/gii/ggt221

17. Zhang XP and Zhang Q. Distinction of crack nature in brittle rock-like materials: a numerical study based on moment tensors. Rock Mech Rock Eng (2017) 50(10):1-9. doi:10.1007/s00603-017-1263-6

18. Ma J, Wu S, Zhang XP, Gan Y. Modeling acoustic emission in the Brazilian test using moment tensor inversion. Comput Geotech (2020) 123:103567. doi:10. 1016/j.compgeo.2020.103567

19. Cundall PA. "A computer model for simulating progressive, large-scale movement in blocky rock system", in Proceedings of the International Symposium on rock mechanics (1971).

20. Cundall PA and Strack ODL. Discussion: a discrete numerical model for granular assemblies. Geotechnique (1980) 30(3):331-6.

21. Li XB, Zou Y, Zhou ZL. Numerical simulation of the rock SHPB test with a special shape striker based on the discrete element method. Rock Mechanics and Rock Engineering (2014) 47(5):1693-709. doi:10.1007/s00603-013-0484-6

22. Zhou ZL, Zhao Y, Jiang YH, Zou Y, Cai X, Li DY. Dynamic behavior of rock during its post failure stage in shpb tests. Trans Nonferrous Metals Soc China (2017) 27(1):184-96. doi:10.1016/S1003-6326(17)60021-9

23. Cai X, Zhou Z, Tan L, Song Z. Fracture behavior and damage mechanisms of sandstone subjected to wetting-drying cycles, Eng Fract Mech (2020) 234: 107109. doi:10.1016/j.engfracmech.2020.107109

24. Dai F, Huang S, Xia KW, Tan Z. Some fundamental issues in dynamic compression and tension tests of rocks using split Hopkinson pressure bar. Rock Mech Rock Eng (2010) 43(6):657-66. doi:10.1007/s00603-010-0091-8

25. Ai DH, Zhao YC, Wang QF, Li CW. Experimental and numerical investigation of crack propagation and dynamic properties of rock in SHPB indirect tension test. Int J Impact Eng (2019) 126:135-46. doi:10.1016/j.ijimpeng.2019.01.001

26. Li DY, Han ZY, Sun XL, Zhou T, Li XB. Dynamic mechanical properties and fracturing behavior of marble specimens containing single and double flaws in
SHPB tests. Rock Mech Rock Eng (2019) 52(6):1623-43. doi:10.1007/s00603018-1652-5

27. Zhou ZL, Zhao Y, Cao WZ, Chen L, Zhou J. Dynamic response of pillar workings Induced by Sudden pillar recovery. Rock Mechanics and Rock Engineering (2018) 51(10):3075-3090. doi:10.1007/s00603-018-1505-2

28. Hazzard JF and Damjanac B. "Further investigations of microseismicity in bonded particle models", in Proceedings of the 3rd International FLAC/DEM Symposium. Minneapolis, MN: Itasca Consulting Group (2013), 22-4.

29. Gutenberg B and Richter CF. Frequency of earthquakes in California. Bull Seismol Soc Am (1944) 34(4):185-8. doi:10.1038/156371a0

30. Itasca Consulting Group Inc. PFC2D (Particle flow Code in 2 dimensions). Minneapolis, Minnesota: ICG (1999).Version 2.0

31. Hanks TC and Kanamori H. A moment magnitude scale. J Geophys Res (1979) 84:2348-2350

32. Feignier B and Young RP. Moment tensor inversion of induced microseisnmic events: evidence of non-shear failures in the $-4<\mathrm{M}<-2$ moment magnitude range. Geophys Res Lett (1992) 19(14):1503-6.

33. Zhang QB and Zhao J. A review of dynamic experimental techniques and mechanical behaviour of rock materials. Rock Mech Rock Eng (2014) 47(4): 1411-78. doi:10.1007/s00603-013-0463-y

34. Ren FQ, Zhu C, He MC. Moment tensor analysis of acoustic emissions for cracking mechanisms during schist strain burst. Rock Mech Rock Eng (2019) 53:1-18. doi:10.1007/s00603-019-01897-3

35. Yamamoto K, Naoi M, Chen YQ, Nishihara K, Yano S, Kawakata H, et al. Moment tensor analysis of acoustic emissions induced by laboratory-based hydraulic fracturing in granite. Geophys J Int (2018) 216(3):1507-16. doi:10. 1093/gji/ggy493

36. Benedetto MF, Berrone S, Pieraccini S, Scialò S. The virtual element method for discrete fracture network simulations. Comput Methods Appl Mech Eng (2014) 280:135-56.

37. Zhang QB and Zhao J. Determination of mechanical properties and full-field strain measurements of rock material under dynamic loads. Int J Rock Mech Min Sci (2013) 60:423-39. doi:10.1016/j.ijrmms.2013.01.005

Conflict of Interest: The authors declare that the research was conducted in the absence of any commercial or financial relationships that could be construed as a potential conflict of interest.

Copyright $\odot 2021$ Zhou, Zhou, Zhao, Chen and Li. This is an open-access article distributed under the terms of the Creative Commons Attribution License (CC BY). The use, distribution or reproduction in other forums is permitted, provided the original author(s) and the copyright owner(s) are credited and that the original publication in this journal is cited, in accordance with accepted academic practice. No use, distribution or reproduction is permitted which does not comply with these terms. 